\title{
Three-year Treatment Outcomes in the Ahmed Baerveldt Comparison Study
}

\author{
Keith Barton, MD ${ }^{1,2}$, William J Feuer, MS $^{3}$, Donald L Budenz, MD, MPH ${ }^{4}$, Joyce Schiffman, \\ MS $^{3}$, Vital P. Costa, MD ${ }^{5}$, David G. Godfrey, MD $^{6}$, and Yvonne M. Buys, MD ${ }^{7, *}$ on behalf of \\ the Ahmed Baerveldt Comparison Study Group \\ ${ }^{1}$ Glaucoma Service, Moorfields Eye Hospital, London, U.K. \\ 2Division of Epidemiology and Genetics, Institute of Ophthalmology, University College London \\ ${ }^{3}$ Department of Ophthalmology, Bascom Palmer Eye Institute, Miller School of Medicine, \\ University of Miami, Miami, FL, USA \\ ${ }^{4}$ Dept of Ophthalmology, University of North Carolina, Chapel Hill, NC, USA \\ ${ }^{5}$ Department of Ophthalmology, University of Campinas, São Paulo, Brazil \\ ${ }^{6}$ Glaucoma Associates of Texas, Dallas, TX, USA \\ ${ }^{7}$ Department of Ophthalmology and Vision Sciences, University of Toronto, Toronto, Ontario, \\ Canada
}

\begin{abstract}
Purpose-To compare three year outcomes and complications of the Ahmed FP7 Glaucoma Valve (AGV) and Baerveldt 101-350 Glaucoma Implant (BGI) for the treatment of refractory glaucoma.
\end{abstract}

Design-Multicenter randomized controlled clinical trial.

Participants-276 patients; 143 in the AGV group and 133 in the BGI group.

Methods-Patients aged 18-85 years with refractory glaucoma and intraocular pressures (IOPs) $\geq 18 \mathrm{mmHg}$ in whom an aqueous shunt was planned were randomized to either an AGV or a BGI.

Main Outcome Measures-IOP, visual acuity, supplemental medical therapy, complications, and failure (IOP > $21 \mathrm{mmHg}$ or not reduced by $20 \%$ from baseline, IOP $\leq 5 \mathrm{mmHg}$, reoperation for glaucoma or removal of implant, or loss of light perception vision).

\footnotetext{
(C) 2014 American Academy of Ophthalmology, Inc. Published by Elsevier Inc. All rights reserved.

CORRESPONDENCE: Donald L Budenz, MD, MPH, Department of Ophthalmology, University of North Carolina, Chapel Hill, NC, USA.

*Members of the study group are listed online at http://aaojournal.org

Publisher's Disclaimer: This is a PDF file of an unedited manuscript that has been accepted for publication. As a service to our customers we are providing this early version of the manuscript. The manuscript will undergo copyediting, typesetting, and review of the resulting proof before it is published in its final citable form. Please note that during the production process errors may be discovered which could affect the content, and all legal disclaimers that apply to the journal pertain.

CONFLICTS OF INTEREST: No conflicting relationship exists for any author
} 
Results-At 3 years, IOP (mean \pm standard deviation) (SD) was $14.3 \pm 4.7 \mathrm{mmHg}$ (AGV group) and $13.1 \pm 4.5 \mathrm{mmHg}$ (BGI group) $(\mathrm{p}=0.086)$ on $2.0 \pm 1.4$ and $1.5 \pm 1.4$ glaucoma medications respectively $(\mathrm{p}=0.020)$. The cumulative probabilities of failure were $31.3 \%$ (standard error $=$ $4.0 \%)(\mathrm{SE})(\mathrm{AGV})$ and $32.3 \%(4.2 \%)(\mathrm{BGI})(\mathrm{p}=0.99)$. Postoperative complications associated with reoperation or vision loss of $\geq 2$ Snellen lines occurred in 24 patients (22\%) (AGV) and 38 patients $(36 \%)(\mathrm{BGI})(\mathrm{p}=0.035)$. The mean change in the Logarithm of the Minimum Angle of Resolution visual acuity (logMAR VA) at 3 years was similar (AGV: $0.21 \pm 0.88$, BGI: $0.26 \pm$ $0.74)$ in the two treatment groups at 3 years $(\mathrm{p}=0.66)$. The cumulative proportion of patients (SE) undergoing reoperation for glaucoma prior to the three year postoperative time point was $14.5 \%$ (3.0\%) in the AGV group compared to $7.6 \%$ (2.4\%) in the BGI group ( $\mathrm{p}=0.053$, log-rank). The relative risk of reoperation for glaucoma in the AGV group was 2.1 times that of the BGI group (95\% Confidence Interval:1.0-4.8, $\mathrm{p}=0.045$; Cox proportional hazards regression).

Conclusions-AGV implantation was associated with the need for significantly greater adjunctive medication to achieve equal success relative to BGI implantation and resulted in a greater relative risk of reoperation for glaucoma. More subjects experienced serious postoperative complications in the BGI group than in the AGV group.

Aqueous shunts are used increasingly in the management of glaucoma in situations where trabeculectomy is unlikely to succeed or has failed. Published data from the United States Medicare database for glaucoma procedures performed between 1995 and 2004 demonstrate a $184 \%$ increase in the number of aqueous shunt procedures. ${ }^{1}$ This trend has continued with a further increase from 7754 shunts in 2004 to 11311 in 2010 (Personal communication, Anne L Coleman - American Academy of Ophthalmology H Dunbar Hoskins Center for Quality Care). The 5 year results of the Tube versus Trabeculectomy Study, which showed a higher success rate with the use of the Baerveldt glaucoma implant (BGI, Abbott Medical Optics, Abbott Park, IL) than with trabeculectomy with adjunctive mitomycin $\mathrm{C}$ in patients with prior failed filtration surgery and/or cataract surgery, has stimulated interest in aqueous shunt implantation in similar patient groups. ${ }^{2 ; 3}$

The Ahmed glaucoma valve (AGV, New World Medical, Cucamonga, CA) and BGI are two of the shunts most commonly used in clinical practice, sharing a common design of a tube that shunts aqueous humor from the anterior chamber to an endplate located at the equatorial region of the globe. Aqueous shunts differ in terms of materials and design features, including the presence or absence of a flow restrictor designed to limit aqueous flow and hence reduce the risk of postoperative low intraocular pressure (IOP). Surgeons choose specific aqueous shunts for various reasons, including perceived efficacy in controlling IOP, perceived risks of complications, and ease of implantation.

There have been several retrospective studies reporting the relative rates of complications and successful IOP control when these implants have been used in refractory glaucomas. ${ }^{4-8}$ The purported advantage of AGV implantation is early postoperative IOP control and reduced risk of hypotony due to a flow restrictor. Although the BGI has no flow restrictor, some believe that certain features of its plate design reduce the tendency to encapsulate. These include its large surface area, low, curved profile, and polished surface. ${ }^{9,10}$ In addition, it has been postulated that complete occlusion of non-valved implants such as the 
BGI for the first four to six weeks postoperatively limits inflammatory mediators from entering the bleb with the consequent reduction in the likelihood of bleb encapsulation. ${ }^{11}$ Success rates reported for the AGV range from 68 to $100 \%$ and for the BGI from $43-100 \%$ with such rates being highly dependent upon the length of follow-up, type of glaucoma, and success criteria. ${ }^{12}$ A recent Ophthalmic Technology Assessment report by the American Academy of Ophthalmology states that "Too few high-quality direct comparisons of various available shunts have been published to assess the relative efficacy or complication rates of specific devices...", ${ }^{13}$ highlighting the need for randomized clinical trials in this area.

Currently two randomized clinical trials have been designed to compare prospectively these two commonly used implants: the Ahmed versus Baerveldt (AVB) Study ${ }^{14}$ and the Ahmed Baerveldt Comparison (ABC) Study. ${ }^{15}$ The Ahmed Baerveldt Comparison (ABC) Study was designed to compare prospectively the safety and efficacy of AGV model FP7 and BGI model 101-350 implantation for refractory glaucoma. Patients with uncontrolled glaucoma who had prior incisional surgery or other glaucoma diagnoses known to be poor candidates for trabeculectomy were enrolled in this multicenter clinical trial and randomized to placement of one of these two implants. The ABC Study has previously reported a comparison of these two implants with one year postoperative follow up. ${ }^{16}$ In this manuscript we report the treatment outcomes of the ABC Study after three years of followup.

\section{METHODS}

The Institutional Review Board at each of 16 Clinical Centers approved the study protocol before recruitment was started, and each patient gave informed consent. The study was registered at www.clinicaltrials.gov (accessed November $24^{\text {th }}$ 2013). The design and methods of the ABC Study are described in detail in a baseline methodology paper, ${ }^{15}$ and are summarized as follows.

\section{Randomization and Treatment}

Eligibility was independently confirmed at the Statistical Coordinating Center (SCC) at the Bascom Palmer Eye Institute. Individuals enrolled in the study were randomized to placement of an AGV FP7 or BGI 101-350 according to a permuted variable block randomization scheme, stratified by surgeon within Clinical Center and type of glaucoma.

Patients aged 18-85 years with refractory glaucoma and intraocular pressures (IOPs) greater than or equal to $18 \mathrm{mmHg}$ in whom an aqueous shunt was planned were randomized to undergo implantation of either an AGV or a BGI. Patients with primary glaucomas with a previous failed trabeculectomy or other intraocular surgery were included. Also, patients without previous intraocular surgery were eligible if they had secondary glaucomas known to have a high failure rate with trabeculectomy such as neovascular, uveitic, or iridocorneal endothelialization syndrome-associated glaucoma.

Enrolled patients were allocated to one of 4 strata according to their type of glaucoma, as follows: (1) Primary glaucomas with previous intraocular surgery; (2) Secondary glaucomas (excluding uveitic and neovascular glaucomas (NVG)); (3) NVG; (4) Uveitic glaucoma. Neither the subject nor investigator was masked to the randomization assignment. Details of 
the surgical procedures for AGV and BGI implantation used in this study are described in the baseline paper. ${ }^{15}$

\section{Patient Visits}

Follow-up visits were scheduled one day, one week, one month, three months, six months, one year, 18 months, two years, three years, four years, and five years postoperatively. Information about data obtained at baseline and follow-up visits is contained in the baseline paper. ${ }^{15}$

\section{Primary and Secondary Outcome Measures}

The outcome measures used in the ABC Study were largely surrogates for patient functional outcomes that were not measured in the study. The primary outcome measure was failure, which was defined prospectively as IOP $>21 \mathrm{mmHg}$ or less than a $20 \%$ reduction below baseline on 2 consecutive study visits after three months, IOP $\leq 5 \mathrm{mmHg}$ on 2 consecutive study visits after three months, reoperation for glaucoma, loss of light perception vision, or removal of the implant for any reason. Reoperation for glaucoma was defined as additional glaucoma surgery requiring a return to the operating room (cyclodestruction was counted as a reoperation for glaucoma whether or not the procedure was performed in the operating room). Interventions performed at the slit lamp, such as needling procedures, removal of occluding stents, or laser suture lysis, were not considered glaucoma reoperations.

IOP and the rate of surgical complications were secondary outcome measures in the ABC Study. Early complications were those that were recorded by the three-month follow-up visit whereas late complications were those that were experienced after the three-month followup visit. A serious complication was defined as any complication, early or late, that was associated with a two line Snellen acuity decrease and/or a return to the operating room for a surgical procedure to manage the complication.

A revision in the operating room to manage an occluded tube was considered a reoperation for a complication. The Snellen visual acuity decrease was assessed at the three-year visit. If the patient did not have a three-year visit, then their complication could not be categorized as serious by vision loss, but could by virtue of reoperation.

\section{Change in definition}

The current manuscript includes a change in the definition of a loss of "two Snellen lines" for those with visual acuities below counting fingers $(\mathrm{CF})$. In the one year treatment outcomes manuscript, ${ }^{17}$ a decrease in acuity from CF to hand motions (HM) and from HM to light perception (LP) was considered as "two Snellen lines" of change. To reflect differing investigators' views on this matter, such a decrease is considered a "one-line" reduction in acuity in this manuscript. CF to HM is therefore considered to be a "one line" reduction in acuity.

\section{Statistical Analysis}

Snellen VA measurements were converted to Logarithm of the Minium Angle of Resolution visual acuity (logMAR VA) equivalents for the purpose of data analysis, as reported 
previously. ${ }^{15 ; 18}$ The time to failure was defined either as the time from surgical treatment to reoperation for glaucoma, loss of acuity to no light perception (NLP) in the study eye, or as the time from surgical treatment to the first of two consecutive follow-up visits after three months in which the patient had persistent hypotony (IOP $\leq 5 \mathrm{mmHg}$ ) or inadequately controlled IOP (IOP > $21 \mathrm{mmHg}$ or not reduced by 20\%). Data on IOP and numbers of glaucoma medications were censored once a subject underwent a reoperation for glaucoma, explantation of the implant for a complication, or loss of light perception vision, but not after failure due to high IOP, hypotony, or reoperation for a complication. There was no censoring of visual acuity results. Univariate comparisons between treatment groups were performed with the two-sided Student t-test for continuous variables and the chi-square test or Fisher's exact test for categorical variables. Risk factors for treatment failure were assessed for statistical significance with the Kaplan-Meier survival analysis log-rank test. Multivariate analysis was performed with Cox proportional hazard regression analysis with forward stepwise elimination. Patients' data were analyzed in the group to which they were assigned during randomization (intent-to-treat analysis). A p-value of 0.05 or less was considered statistically significant.

\section{RESULTS}

\section{Recruitment and Retention}

A total of 276 patients were enrolled between October 2006 and April 2008. 143 patients (52\%) were randomly assigned to placement of an AGV and $133(48 \%)$ to a BGI. Protocol violations are described in the baseline paper. ${ }^{15}$ All patients were analyzed in the group to which they were originally assigned according to the intent-to-treat protocol.

Retention of patients in the study at three years is illustrated in Figure 1. In the overall study group, $223(81 \%)$ patients attended at least three years of follow-up. This included 113 (79\%) patients in the AGV group and $110(83 \%)$ in the BGI group. $106(74 \%)$ AGV patients completed the actual three-year visit compared to 100 (75\%) BGI patients. The number of patients completing each follow-up visit is shown in Table 1.

We compared patients who returned for three year visits $(n=144)$ to those who did not $(n=39)$, excluding from analysis those who had died prior to the end of the 3 year visit window $(\mathrm{n}=10)$ and those who had previously been classified as failing pressure control $(\mathrm{n}=83)$. Participants not returning for 3 year visits were more likely to have neovascular glaucoma ( $\mathrm{p}<0.001)$; be of Hispanic ethnicity $(\mathrm{p}<0.044)$; have higher intraocular pressures at baseline $(\mathrm{p}=0.048)$ and year $2(\mathrm{p}=0.022)$ but not year $1(\mathrm{p}=0.30)$ of follow up; and have worse visual acuity at baseline $(\mathrm{p}=0.069)$, year $1(\mathrm{p}=0.032)$, and year $2(\mathrm{p}<0.034)$. However patients failing to return for 3 year follow up were not different with respect to gender $(\mathrm{p}=0.37)$, age $(\mathrm{p}=0.18)$, ethnicity $(\mathrm{p}=0.26)$, or randomized treatment group $(\mathrm{p}=1.00)$. Thus, whatever selection biases lead to differential follow up, they should not affect the randomized treatment comparison. 


\section{Baseline Characteristics}

There were no differences in baseline demographic or clinical characteristics between the two groups as detailed in the baseline paper. ${ }^{15}$

\section{IOP Reduction}

The baseline and follow-up IOPs for the two groups are reported in Table 1 and Figure 2. Patients who underwent additional glaucoma surgery were censored from analysis after the time of reoperation, as were those undergoing explantation for any reason and those who lost light perception in the study eye. Both study groups experienced a significant reduction in IOP. In the AGV group, IOP (mean \pm standard deviation; SD) reduced from $31.2 \pm 11.2$ $\mathrm{mmHg}$ at baseline to $14.3 \pm 4.7 \mathrm{mmHg}$ at the three-year follow-up visit $(\mathrm{p}<0.001$, paired ttest). In the BGI group, IOP (mean $\pm \mathrm{SD}$ ) was reduced from $31.8 \pm 12.5 \mathrm{mmHg}$ at baseline to $13.1 \pm 4.5 \mathrm{mmHg}$ at the three-year follow-up visit ( $\mathrm{p}<0.001$, paired $\mathrm{t}$-test). The IOP difference between the two treatment arms at three years was not statistically significant $(\mathrm{p}=0.086)$. The AGV group had a significantly lower mean IOP than the BGI group at the one day and one week follow-up visits, the mean IOP in the BGI group was approximately 1 to $2 \mathrm{mmHg}$ lower than the $\mathrm{AGV}$ group thereafter except at the two-year visit.

\section{Medical Therapy}

Table 1 also shows the number of glaucoma medications in both groups at baseline and follow-up. Patients who underwent additional glaucoma surgery were censored from analysis after the time of reoperation. There was a significant reduction in the need for medical therapy in both treatment groups (Figure 3). The number of glaucoma medications (mean $\pm \mathrm{SD}$ ) in the $\mathrm{AGV}$ group decreased from $3.4 \pm 1.1$ at baseline to $2.0 \pm 1.4$ at the three-year follow-up visit ( $<<0.001$, paired t-test). The number of glaucoma medications (mean $\pm \mathrm{SD}$ ) in the BGI group was reduced from $3.5 \pm 1.1$ at baseline to $1.5 \pm 1.4$ at the three-year follow-up visit ( $p<0.001$, paired t-test). Subjects in the AGV group were using significantly more mediations at both two and three years as compared to the BGI group ( $\mathrm{p}$ $=0.020$ for each).

\section{Treatment Outcomes}

Table 2 compares the outcomes and reasons for failure of randomized patients, unadjusted for follow-up time. All patients who were seen at the three-year follow-up visit and/or failed during the first three years of the study were included in this analysis. While the total numbers of failures were similar in the two groups, the number failing due to uncontrolled high IOP or reoperation for glaucoma was 34 in the AGV group (representing 79\% of AGV failures) compared to 22 in the BGI group (55\% of BGI failures), a statistically significant difference ( $\mathrm{p}=0.034)$. An alternative statement of this result is that only 9 AGV eyes ( $21 \%$ of AGV failures) experienced persistent hypotony, complications for which explantation was performed, or losing light perception in the study eye compared to 18 (45\% of failures) in the BGI group.

Kaplan-Meier survival analysis was used to compare failure rates between the two treatment groups (Figure 4). The cumulative probability of failure (standard error) (SE) was $31.3 \%$ (4.0\%) in the AGV group and 32.3\% (4.2\%) in the BGI group at three years ( $\mathrm{p}=0.99$, log- 
rank test). The relative risk of treatment failure in the AGV group was 1.0 times that in the BGI group (95\% Confidence Interval (CI): 0.7-1.6, $\mathrm{p}=0.99$ Cox proportional hazards regression). There was no suggestion of different treatment effects in the four randomized strata $(p=0.72$, three degree of freedom test of treatment group by stratum interaction).

The cumulative proportion of patients (SE) undergoing reoperation for glaucoma prior to the three year postoperative timepoint was $14.5 \%$ (3.0\%) in the AGV group compared to $7.6 \%$ $(2.4 \%)$ in the BGI group ( $\mathrm{p}=0.053$, log-rank test; figure 4$)$. The relative risk of reoperation for glaucoma in the AGV group was 2.1 times that of the BGI group (95\% CI:1.0-4.8, $\mathrm{p}=0.045$; Cox proportional hazards regression).

The failure rates for the two treatment groups were examined with alternative outcome criteria. Patients with persistent hypotony, reoperation for glaucoma, or loss of light perception vision were still classified as treatment failures; however, the upper IOP limit defining success and failure was changed. When inadequate IOP control was defined as IOP greater than $17 \mathrm{mmHg}$ or not reduced by $20 \%$ on two consecutive follow-up visits after three months, the cumulative probability of failure at three years was $44.3 \%(4.3 \%)$ in the AGV group and $36.9 \%(4.3 \%)$ in the BGI group $(\mathrm{p}=.17$, stratified log rank test). When inadequate IOP control was defined as IOP greater than $14 \mathrm{mmHg}$ or not reduced by $20 \%$ on two consecutive follow-up visits after three months, the cumulative probability of failure was $67.2 \%(4.0 \%)$ in the AGV group and $52.6 \%$ in the BGI group at three years $(\mathrm{p}=.003$, stratified log rank test).

Patients with a three-year follow up visit who were still successful through that visit were divided into complete and qualified success based on the requirement for IOP-lowering medical therapy at three years. The number (\%) of complete successes at three years was 15 $(20 \%)$ in the AGV group compared to $23(33 \%)$ in the BGI group ( $p=0.093$, Fisher exact test).

Because the surgeon was not masked to the treatment assignment, a potential bias existed in the decision to reoperate for IOP control. To evaluate for reoperation bias, the IOP levels were compared between treatment groups among patients who failed because of inadequate IOP control. For cases failing by high IOP at two consecutive study visits (e.g. 6 and 12 months or 18 and 24 months) without reoperation, the average of the failing IOPs was calculated and compared between the two randomized groups. The average (SD) failing IOP in the AGV group was $21.5 \mathrm{mmHg}$ (6.3) compared to 23.2 (8.4) in the BGI group ( $\mathrm{p}=0.51$, two-sample t-test). Among AGV cases reoperated for glaucoma the mean (SD) preoperative IOP immediately prior to reoperation was 32.4 (10.8) compared to 24.9 (5.6) in the BGI group ( $\mathrm{p}=0.094)$. Although not statistically significant, this latter difference suggests a possibly higher, rather than lower, threshold for reoperation in the $\mathrm{AGV}$, compared to the BGI, group.

\section{Visual Acuity}

Visual acuity results are shown in Table 3. There was a significant decrease in Snellen VA in both treatment groups during the first three years of follow-up. In the AGV group, $\log$ MAR Snellen VA (mean \pm SD) decreased from $1.07 \pm 1.01$ at baseline to $1.16 \pm 1.07$ at 
the three-year follow-up visit ( $\mathrm{p}=0.019$, paired $\mathrm{t}$-test). In the BGI group, $\log$ MAR Snellen VA (mean $\pm \mathrm{SD}$ ) decreased from $1.04 \pm 1.00$ at baseline to $1.19 \pm 1.28$ at the three-year follow-up visit ( $\mathrm{p}=.001$, paired $\mathrm{t}$-test). There was no significant difference in logMAR Snellen VA ( $p=0.75$, student t-test) between the two groups at three years.

Snellen VA was decreased by two or more lines from baseline in $36(35 \%)$ patients in the AGV group and 30 (30\%) patients in the BGI group at three years, and this difference in rate of vision loss between treatment groups was not statistically significant $(p=0.46$, Fisher's exact test). The most frequent causes of vision loss during three years of follow-up were glaucoma, retinal disease, and cataract. The reason for decreased vision was unknown in 4 (11\%) patients in the AGV group and 1 (3\%) patients in the BGI group. Other miscellaneous causes for reduced vision in eight patients in the AGV group included vitreous hemorrhage, corneal epithelial defect, retinal detachment, diabetic retinopathy, band keratopathy, and neovascular membrane. Other causes of vision loss in 11 patients in the BGI group included corneal edema, retinal detachment, diabetic retinopathy, endophthalmitis, and posterior capsular opacification. There were no significant differences in the reasons for visual acuity loss between the two groups.

\section{Postoperative Interventions}

The most frequently performed postoperative intervention between the 18 month and three year postoperative time points was cataract extraction. The total number of interventions was 15 in the AGV group and 17 in the BGI group, a difference which was not statistically significant ( $\mathrm{p}=0.50$, Chi-squared test).

\section{Postoperative Complications}

Table 4 shows the cumulative proportions of late complications at three years in each treatment group. Fifty five patients $(44.7 \%)$ in the AGV group developed a late complication, compared with $63(61.5 \%)$ in the BGI group $(\mathrm{p}=0.13, \log$ rank). The rate of phthisis bulbi was significantly higher in the BGI group ( 0 vs 5 (or 3.6\%), p=0.023 log rank). At three years there was also a significant difference in tube occlusion between the two groups, with $1(0.8 \%)$ in the AGV group, and $6(4.9 \%)$ in the BGI group ( $\mathrm{p}=0.039 \log$ rank). Fourteen eyes (12.4\%) in the AGV group had corneal edema at 3 years compared with $15(15.7 \%)$ BGI eyes ( $\mathrm{p}=0.51)$. In order to determine the likelihood of corneal edema related to the aqueous shunt, one investigator (DLB) re-examined all of the data collection forms retrospectively masked to treatment assignment and early postoperative visits to exclude patients with corneal edema related to pre-existing corneal disease. As a result, we concluded that seven $(6.4 \%)$ of $\mathrm{AGV}$ and nine $(10.1 \%)$ of BGI had corneal edema ( $\mathrm{p}=0.42$ $\log$ rank) that was not attributable to underlying corneal disease. These figures exclude patients who had early postoperative corneal edema that subsequently resolved.

The number of patients experiencing serious complications, defined a priori as complications that required a return to the operating room to manage the complication and/or associated with loss of two or more lines of Snellen visual acuity, was significantly higher in the BGI group $(n=38,36 \%)$ than in the AGV group $(n=24,20 \%, p=0.035)$. 
Table 5 shows complications by NVG versus other strata. Table 6 provides complete data for serious complications.

\section{Reoperation for Complications}

Reoperations for complications (Table 6), including explantations, were performed in 12 (11\%) patients in the AGV group and $21(20 \%)$ patients in the BGI group. At year three, the cumulative proportion (SE) of complication-related reoperations in the AGV group was 9.2\% (2.5\%) compared to $16.6 \%$ (3.3\%) in the BGI group ( $\mathrm{p}=0.060$, log-rank test). In the AGV group, reasons for complication-related reoperations included: revise exposed tube (1), reposition the tube (1), place tube extender (2), new patch graft (1), and removal of occlusions (3), repair wound leak (1). In addition there were three explantations in the AGV group, two for diplopia and one for extrusion. In the BGI group, the reasons for reoperation for complications included: removal of occlusions (7), repair patch graft (1), repair tube erosion (2), repair bleb leak (1), reposition tube (1), ligate tube for over-filtration (1), and drain suprachoroidal hemorrhage (1), pars plana vitrectomy (2) and penetrating keratoplasty (1). In addition there were four explantations, one for chronic endophthalmitis, one for corneal touch, one for exposure and one for chronic pain.

\section{Cataract Surgery during Follow-Up}

There were 92 phakic patients in the study, 47 in the AGV group and 45 in the BGI group. The cumulative proportion (SE) undergoing cataract extraction in the AGV group was $40.6 \%(8.3 \%)$ compared to $40.1 \%(7.9 \%)$ in the BGI group ( $\mathrm{p}=0.79$, log rank test).

\section{DISCUSSION}

The primary outcome measure of the ABC Study was failure to control IOP, defined prospectively as IOP $>21 \mathrm{mmHg}$ or less than a $20 \%$ reduction below baseline on 2 consecutive study visits after three months, IOP $\leq 5 \mathrm{mmHg}$ on 2 consecutive study visits after three months, reoperation for glaucoma, loss of light perception vision, or removal of the implant for any reason. There was no statistically significant difference between the two implant groups with regard to the primary outcome measure. Both procedures lowered IOP and medication use significantly at three years from baseline. The AGV group had a higher rate of reoperation for glaucoma than the BGI group (Table 2) but this was of borderline significance $(\mathrm{p}=0.054)$. The mean IOP was $1.2 \mathrm{mmHg}$ lower at three years with the BGI. Although this difference was not statistically significant $(\mathrm{p}=0.086)$ it is noteworthy the BGI group was also receiving fewer postoperative IOP lowering medications at the three year time point, a difference which was statistically significant. $(\mathrm{p}=0.020)$.

Seventy nine percent of AGV failures occurred as a result of high IOP or reoperation for high IOP (Table 2), whereas $46 \%$ of BGI failures were due to low IOP or surgery-related complications. We checked for a systematic difference in the threshold for reoperation for high IOP and found that the higher threshold for reoperation in the AGV group than the BGI group was not statistically significant. If such a bias existed, it favored the AGV.

When an alternative outcome based on an upper limit for IOP $\geq 14 \mathrm{mmHg}$ or $<20 \%$ reduction from baseline was tested, ${ }^{19}$ the BGI was significantly more successful than the 
AGV in meeting this lower IOP target ( $\mathrm{p}=.003$ ). However, in this study neither device had notable success at achieving such low IOP levels: the AGV failed in $67.2 \%$ and the BGI failed in $52.6 \%$. These high levels of failure are no doubt explained by the high risk case mix recruited for the ABC Study. In the TVT Study (where the BGI was the only implant used, and where the case mix was lower risk), low IOP's, comparable to trabeculectomy, were commonly achieved with the BGI. SSSS ${ }^{20}$ In comparison with the TVT Study, it is interesting to note that although the IOP at baseline was higher in the ABC BGI group (31.8 $\pm 12.5 \mathrm{mmHg})$ than the TVT BGI group $(25.1 \pm 5.3 \mathrm{mmHg})$, the IOP levels at 3 years were very similar in the two studies at $13.0 \pm 4.9 \mathrm{mmHg}$ on $1.3 \pm 1.3$ glaucoma medications in the TVT BGI group and $13.1 \pm 4.5 \mathrm{mmHg}$ on $1.5 \pm 1.4$ glaucoma medications in the ABC BGI group. With similar failure definitions in the two studies, $15 \%$ failed at 3 years in the TVT BGI group, with $54 \%$ qualified successes and $31 \%$ complete successes. In the ABC BGI group, the equivalent figures were $40 \%$ failing at 3 years, $27 \%$ qualified successes and $33 \%$ complete successes.

Figure 5 suggests that Ahmed valves required reoperations at a rate of about $8 \%$ per year beginning in the early post-perioperative period. Baerveldt implants appeared to fail at a similar rate, but with onset delayed until about 18 months following implantation. The planned 5 year data analysis may indicate whether the Kaplan-Meier reoperation curves converge in late follow up.

The number of serious complications at three years was similar in the two groups, except for 5 cases of phthisis bulbi in the BGI group compared with none in the AGV group ( $\mathrm{p}=0.023$ log rank) (Table 4). Table 5 illustrates a breakdown of complications between the neovascular glaucoma (NVG) stratum and other strata, and it can be seen that a number of complications, including corneal edema, phthisis bulbi, hyphema and vitreous hemorrhage were statistically significantly more common in the NVG stratum. Specifically, 4 out of 5 eyes developing phthisis bulbi by three years were in the NVG stratum. Although NVG eyes perform less well, we did not observe a difference in treatment efficacy between the two treatment groups in this stratum. We did not specifically attempt to decide whether complications were attributable to the aqueous shunt as opposed to underlying diagnosis except in the case of corneal edema, as described above.

It is worth noting that in the one year treatment outcome manuscript, a reduction in VA from CF to HM, or HM to LP, was considered a two line loss, whereas in the three-year analysis we have recorded these changes as a one line loss. The mean logMAR visual acuity had decreased in both treatment groups during the first year of follow-up, ${ }^{15}$ but improved slightly in each by three years (Table 3). The proportion of subjects losing 2 or more lines of Snellen acuity was similar at one year (30\% of AGV and 34\% of BGI) and three years (35\% of AGV and 30\% of BGI). Most of the causes of loss of two or more Snellen lines were related to cataract, retinal disease and glaucoma and were not directly attributable to the surgical procedures under study (Table 3 ).

In comparison with the BGI arm of the TVT Study, complications were reported in a higher proportion of ABC Study patients at 3 years $(51.5 \%$ in the BGI group and $44.7 \%$ in the AGV group), than in the former (39\%). This is not unexpected given that many patients 
enrolled in the ABC Study suffered from conditions with a poorer visual prognosis and higher tendency to complications, than in the TVT study.

Tube occlusion and phthisis bulbi, which were substantially more common in the ABC BGI group were reported in 3\% (tube occlusions) of the BGI group in the TVT study and $0 \%$ (phthisis bulbi) in the TVT study. The tube occlusion rate in the TVT study was therefore closer to that of the BGI than AGV group in the ABC study. The reporting of no cases of phthisis bulbi in the TVT Study is in keeping with the observation that 4 out of 5 cases in the ABC BGI group suffered from neovascular glaucoma, an exclusion criterion for the TVT study.

Interestingly many complications commonly associated with tubes (dipopia, corneal edema and erosion) were similar but slightly lower in the ABC than TVT Study. Diplopia was reported in 5\% of TVT Baerveldts compared with $2.8 \%$ in each arm of ABC. Corneal edema was observed in $9 \%$ of TVT tubes, but $3.9 \%$ of $\mathrm{ABC}$ BGI and $3.1 \%$ of ABC AGV. Erosion was observed in $5 \%$ of TVT Baerveldts compared with $0.9 \%$ ABC BGI and $1.1 \%$ of $\mathrm{ABC}$ AGV.

In summary, the ABC Study observed a 54\% reduction in IOP in enrolled eyes at three years, with a similar rate of treatment failure in the two treatment groups, though most AGV failures (79\%) were for high IOP, while most BGI failures (55\%) were for low IOP or complications. The BGI group had slightly lower IOPs at three years on significantly fewer ocular hypotensive medications. While the rate of complications was not significantly different between the two groups, the BGI group were more likely to be reoperated for a complication or suffer 2 or more lines of Snellen vision loss. The rates of a number of serious complications were higher in the NVG stratum than other strata, though we observed no difference in the treatment efficacy between study groups within the NVG stratum.

The ABC Study has much in common with the Ahmed versus Baerveldt (AVB) Study, a randomized surgical trial comparing the same two implants. ${ }^{14 ; 16}$ The AVB Study randomized 238 patients (124 to the AGV and 114 to the $\mathrm{BGI}$ ) with similar but slightly broader patient eligibility to the ABC Study. There were minor demographic differences with a slight female preponderance in the BGI group and more white patients in the AVB Study, with slightly more POAG (50\% versus $40 \%$ ) and less NVG (21\% versus $29 \%$ ) compared with $\mathrm{ABC}$. The AVB Study differed from $\mathrm{ABC}$ in that all surgeons were experienced users of both types of implants and that treatment allocation was decided by a coin toss. In their primary outcome measure, the AVB Study investigators used a more stringent cut-off of $>18 \mathrm{mmHg}$ for high pressure failure and a slightly less stringent limit of $<5 \mathrm{mmHg}$ for hypotony (cf. $>21 \mathrm{mmHg}$ and $<6 \mathrm{mmHg}$ in the ABC Study) and additionally included sight-threatening complications in its definition of failure.

At present, it is possible to compare treatment outcomes at one year between the two studies. Retention was similar in both. The reported cumulative probability of failure was higher with the AGV in both studies but only significantly higher in AVB (AVB: $\mathrm{p}=0.049, \mathrm{ABC}: \mathrm{p}$ $=0.52$ ). AGV IOPs were higher than BGI in both studies (both $\mathrm{p}<0.01$ ) and the AGV group averaged $0.4(\mathrm{AVB}, \mathrm{p}=0.03)$ and $0.3(\mathrm{ABC}, \mathrm{p}=0.07)$ more medications than the $\mathrm{BGI}$ group. 
The reported failure rate of $43 \%$ in the AGV group compared with $28 \%$ in the BGI group in the AVB Study are higher than the corresponding failure rates of $16 \%$ and $14 \%$ respectively in the ABC Study. Potential explanations for this could include the more stringent upper IOP limit and inclusion of sight-threatening complications in the definition of failure in the AVB study. However, when the two studies are compared with the alternative IOP end-point of $\geq 18 \mathrm{mmHg}$ that was also reported by the ABC Study group, and which is close to the definition of $>18 \mathrm{mmHg}$ used by the AVB Study, and when sight-threatening complications are removed from the definition of failure in the AVB Study, the corresponding failure rates for the BGI are 24\% (AVB) and 16\% (ABC), and for the AGV remain at $41 \%$ (AVB) and $22 \%(\mathrm{ABC})$.

In contrast to the ABC Study that reported more complications in the BGI than AGV group, no significant difference in overall number of complications between the two groups was observed in the AVB Study, though significantly more patients required reintervention in the BGI group. A comparison of individual complications reveals some similarities between the two studies: $10 \%$ more corneal edema in the BGI group than in the AGV group (both studies $\mathrm{p}<0.05$ ) and more tube obstruction in BGI group (AVB 6\%, $\mathrm{p}=0.12$ and $\mathrm{ABC} 7 \%, \mathrm{p}=0.02$ ) than in the AGV group. The AVB Study reported an $8 \%$ higher rate of encapsulated blebs in the AGV group than in the BGI group $(\mathrm{p}=0.01)$.

Motility disturbances with the AGV were similar to the ABC Study at $6 \%$ in the AGV group in both studies. The rate of motility disturbance listed in the AVB Study with the BGI was $3 \%$ at one year, compared with 5\% reporting diplopia in the ABC Study. It is interesting to note that the prevalence of dioplopia at three years in the ABC Study appeared to diminish as compared to one year ( $2.8 \%$ in each treatment arm). Once a motility disturbance appeared it was included in the cumulative incidence rate (table 4); however the cross sectional rate at 3 years was lower than at one year. This was due both to removal of the implants, complications were censored after removal of the study implant and such cases would not be included in either the numerator or denominator of the cross-sectional 3 year rate, but also because of spontaneous resolution of symptoms when that occurred, which it did in some patients.

In the longer term the combined data of these two similar studies should provide a valuable insight into the relative benefits and drawbacks of these two implants. Currently, the three year treatment outcomes of the ABC Study do not demonstrate clear superiority of one implant over the other, although the trend towards greater efficacy in the BGI group with fewer complications in the AGV group that was observed at one year is still present at three years. The ABC Study is designed to continue follow-up of participants out to five years.

\section{Acknowledgments}

SUPPORTED BY: NIH P30 EY014801 and unrestricted grants from Research to Prevent Blindness and New World Medical, Inc.

Dr Barton is part funded by the National Institute of Health Research Biomedical Research Centre for Ophthalmology at Moorfields Eye Hospital. 


\section{References}

1. Ramulu PY, Corcoran KJ, Corcoran SL, Robin AL. Utilization of various glaucoma surgeries and procedures in Medicare beneficiaries from 1995 to 2004. Ophthalmology. 2007; 114:2265-2270. [PubMed: 17466376]

2. Gedde SJ, Schiffman JC, Feuer WJ, et al. Tube versus Trabeculectomy Study Group. Treatment outcomes in the Tube Versus Trabeculectomy (TVT) Study after five years of follow-up. Am J Ophthalmol. 2012; 153:789-803. [PubMed: 22245458]

3. Gedde SJ, Herndon LW, Brandt JD, et al. Tube Versus Trabeculectomy Study Group. Postoperative complications in the Tube Versus Trabeculectomy (TVT) Study during five years of follow-up. Am J Ophthalmol. 2012; 153:804-814. [PubMed: 22244522]

4. Tsai JC, Johnson CC, Dietrich MS. The Ahmed shunt versus the Baerveldt shunt for refractory glaucoma: a single-surgeon comparison of outcome. Ophthalmology. 2003; 110:1814-1821. [PubMed: 13129882]

5. Syed HM, Law SK, Nam SH, et al. Baerveldt-350 implant versus Ahmed valve for refractory glaucoma: a case-controlled comparison. J Glaucoma. 2004; 13:38-45. [PubMed: 14704542]

6. Wang JC, See JL, Chew PT. Experience with the use of Baerveldt and Ahmed glaucoma drainage implants in an Asian population. Ophthalmology. 2004; 111:1383-1388. [PubMed: 15234141]

7. Tsai JC, Johnson CC, Kammer JA, Dietrich MS. The Ahmed shunt versus the Baerveldt shunt for refractory glaucoma II: longer-term outcomes from a single surgeon. Ophthalmology. 2006; 113:913-917. [PubMed: 16751034]

8. Goulet RJ III, Phan AD, Cantor LB, WuDunn D. Efficacy of the Ahmed S2 glaucoma valve compared with the Baerveldt 250-mm2 glaucoma implant. Ophthalmology. 2008; 115:1141-1147. [PubMed: 18164068]

9. Heuer DK, Lloyd MA, Abrams DA, et al. Which is better? One or two? A randomized clinical trial of single-plate versus double-plate Molteno implantation for glaucomas in aphakia and pseudophakia. Ophthalmology. 1992; 99:1512-1519. [PubMed: 1454316]

10. Choritz L, Koynov K, Renieri G, et al. Surface topographies of glaucoma drainage devices and their influence on human tenon fibroblast adhesion. Invest Ophthalmol Vis Sci. 2010; 51:40474053. [PubMed: 20207971]

11. Freedman J, Iserovich P. Pro-inflammatory cytokines in glaucomatous aqueous and encysted Molteno implant blebs, and their relationship to pressure. Invest Ophthalmol Vis Sci. 2013; 54:4851-4855. [PubMed: 23788371]

12. Schwartz KS, Lee RK, Gedde SJ. Glaucoma drainage implants: a critical comparison of types. Curr Opin Ophthalmol. 2006; 17:181-189. [PubMed: 16552254]

13. Minckler DS, Francis BA, Hodapp EA, et al. Aqueous shunts in glaucoma: a report by the American Academy of Ophthalmology. Ophthalmology. 2008; 115:1089-1098. [PubMed: 18519069]

14. Christakis PG, Tsai JC, Zurakowski D, et al. The Ahmed Versus Baerveldt Study: design, baseline patient characteristics, and intraoperative complications. Ophthalmology. 2011; 118:2172-2179. [PubMed: 21906813]

15. Barton K, Gedde SJ, Budenz DL, et al. The Ahmed Baerveldt Comparison Study: methodology, baseline patient characteristics, and intraoperative complications. Ophthalmology. 2011; 118:435442. [PubMed: 20932581]

16. Christakis PG, Kalenak JW, Zurakowski D, et al. The Ahmed Versus Baerveldt Study: one-year treatment outcomes. Ophthalmology. 2011; 118:2180-2189. [PubMed: 21889801]

17. Budenz DL, Barton K, Feuer WJ, et al. Ahmed Baerveldt Comparison Study Group. Treatment outcomes in the Ahmed Baerveldt Comparison Study after 1 year of follow-up. Ophthalmology. 2011; 118:443-452. [PubMed: 20932583]

18. Fluorouracil Filtering Surgery Study Group. Five-year follow-up of the Fluorouracil Filtering Surgery Study. Am J Ophthalmol. 1996; 121:349-66. [PubMed: 8604728]

19. Heuer, DK.; Barton, K.; Grehn, F., et al. Consensus on definitions of success. Guidelines on Design and Reporting of Glaucoma Surgical Trials. Shaarawy, TM.; Sherwood, MB.; Grehn, F., editors. Amsterdam, The Netherlands: Kugler; 2009. p. 15-24.Available at: http://www.icoph.org/ 
resources/148/Guidelines-on-Design-and-Reporting-of-Glaucoma-Surgical-Trials.html [Accessed January 8, 2014]

20. Gedde SJ, Schiffman JC, Feuer WJ, et al. Tube Versus Trabeculectomy Study Group. Three-year follow-up of the Tube Versus Trabeculectomy Study. Am J Ophthalmol. 2009; 148:670-684.

[PubMed: 19674729]

\section{The Ahmed versus Baerveldt Comparison Study Group}

\section{Clinical Centers:}

Duke University Eye Center, Leon Herndon, MD;

Glaucoma Associates of Texas, David Godfrey, MD, Ronald Fellman, MD;

Medical College of Wisconsin, The Eye Institute, James Robinson, MD, David Dueker, MD;

Minnesota Eye Consultants, Patrick Riedel, MD , Thomas Samuelson, MD;

NIHR Biomedical Research Centre for Ophthalmology, Moorfields Eye Hospital, Keith Barton, MD, Renata Puertas, MD

National University Hospital, Department of Ophthalmology, Paul Chew, MD, Cecilia Aquino, MD

Southern California Glaucoma Consultants, Alfred M Solish, MD;

Toronto Western Hospital Eye Clinic, Yvonne Buys, MD, Graham Trope, MD;

University of California Davis Medical Center, Department of Ophthalmology, James Brandt, MD, Michele Lim, MD;

University of California Los Angeles, Jules Stein Eye Institute, Simon Law, MD;

University of Campinas, Ophthalmology, Vital Costa, MD;

University of Miami, Bascom Palmer Eye Institute, Donald Budenz, MDi, Steven Gedde, MD, Fouad El Sayyad, MD

University of Oklahoma, Dean A. McGee Eye Institute, Steve Sarkisian, MD

University of Southern California, Doheny Eye Institute, Vikas Chopra, MD, Brian Francis, MD, Mario Meallet, MD, Rohit Varma, MDii

University of Tennessee at Memphis, Department of Ophthalmology, Peter Netlandiii, MD, $\mathrm{PhD}$, Sarwat Salim, MD

University of Texas Houston, Cizik Eye Clinic, Robert Feldman, MD, Nicholas Bell, MD

Safety and Data Monitoring Committee, Voting Members: Philip Chen, MD, University of Washington, Department of Ophthalmology; Dale Heuer, MD, Medical College of

Ophthalmology. Author manuscript; available in PMC 2015 August 01. 
Wisconsin, The Eye Institute; Kuldev Singh, MD, MPH, Stanford University; Martha Wright, MD, University of Minnesota, Department of Ophthlmology. Non-voting members: Donald L Budenz, MD, William J. Feuer, MS, Joyce C. Schiffman, MS

Steering Committee: Keith Barton, MD, Donald L Budenz, MD, MPH, William J. Feuer, MS.

Statistical Coordinating Center: William J. Feuer, MS, Joyce C. Schiffman, MS, Wei Shi, MS; Coordinator, Luz Londono; Database Manager, Yolanda Silva, BS, University of Miami, Bascom Palmer Eye Institute.

${ }^{\mathrm{i}}$ Currently affiliated with University of North Carolina at Chapel Hill

ii Currently affiliated with University of Illinois Chicago

iii Currently affiliated with University of Virginia 


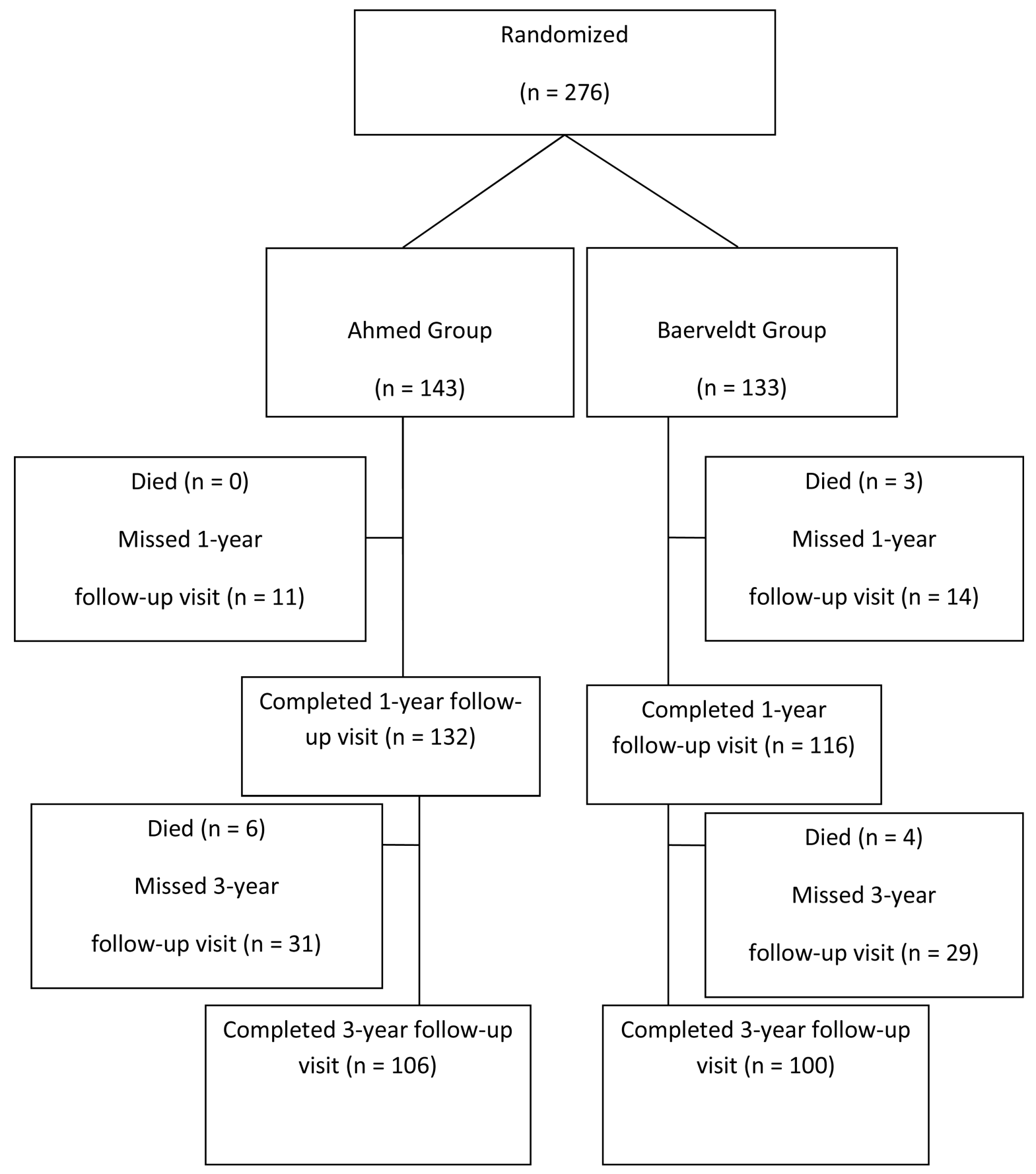

Figure 1. Study Flow Diagram

Recruitument and retention in the ABC study at three years. 


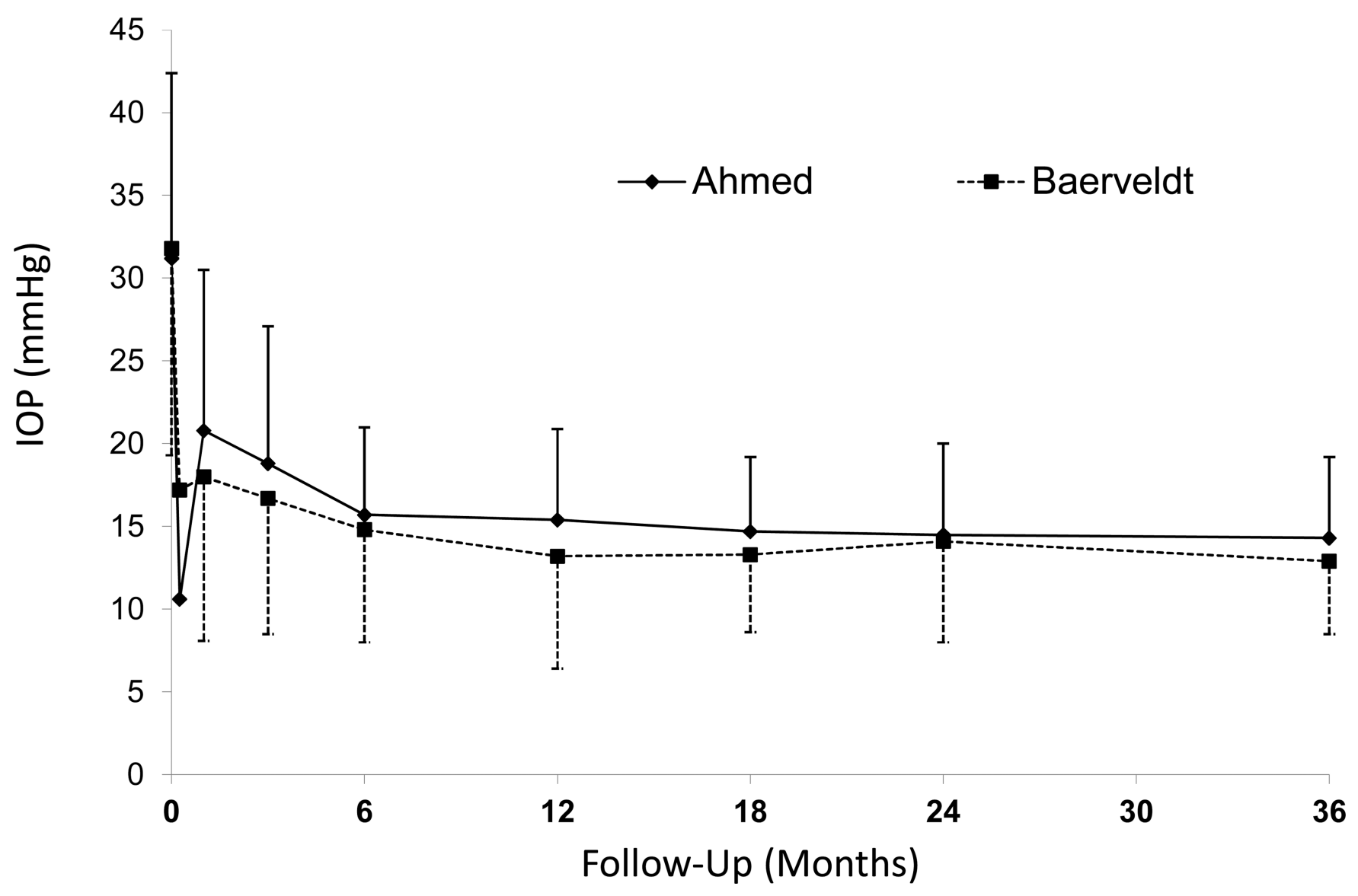

Figure 2. Intraocular Pressure (IOP) by randomized treatment group and follow-up visit Graph of IOP (mmHg) in the Ahmed Baerveldt Comparison (ABC) Study by study group from preoperative level to last follow-up (mean \pm standard deviation (SD)) 


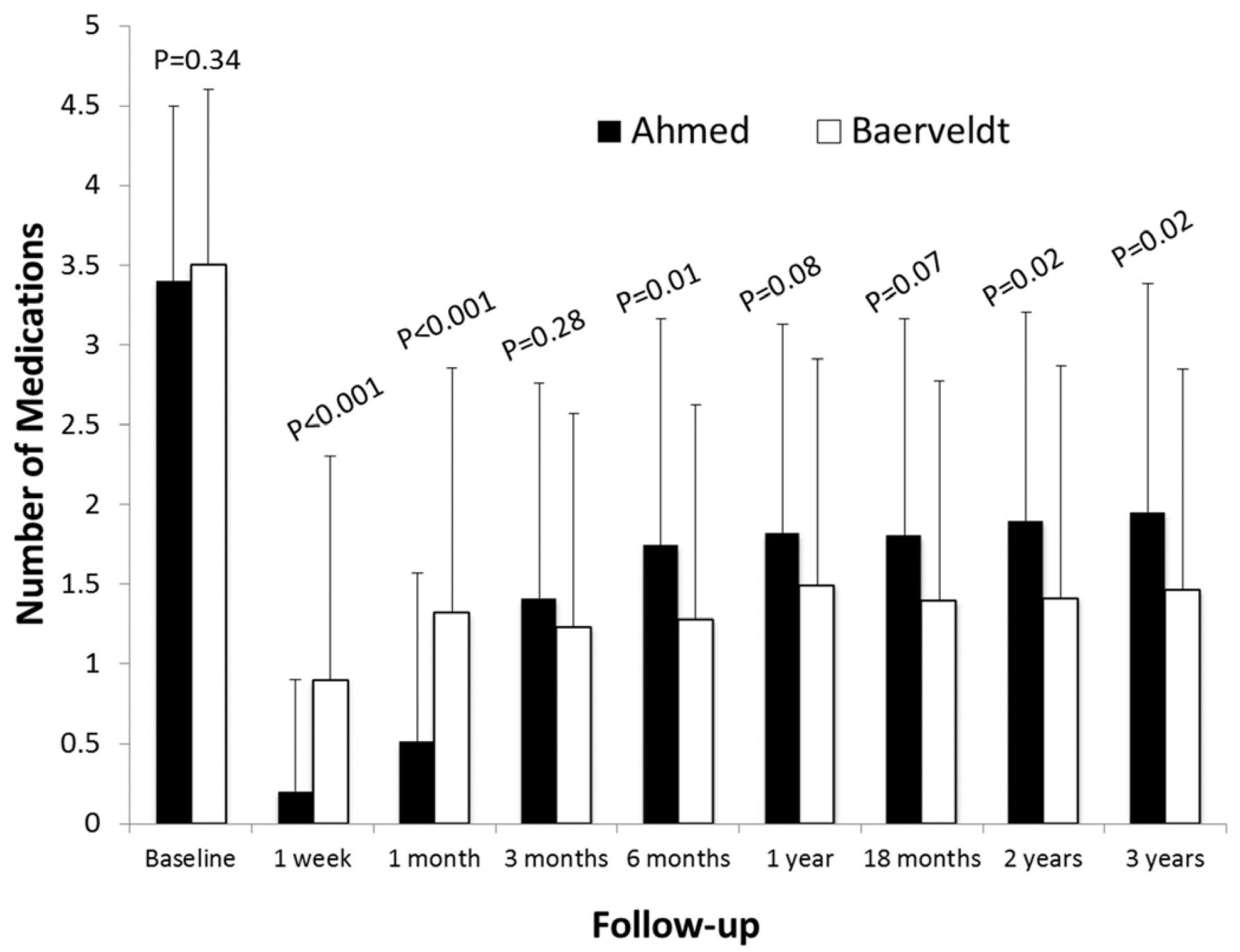

Figure 3. Medication use by randomized treatment group and follow-up visit Histogram of the number of classes of ocular hypotensive medication used from before surgery to three year follow-up visit (mean \pm standard deviation (SD)) 


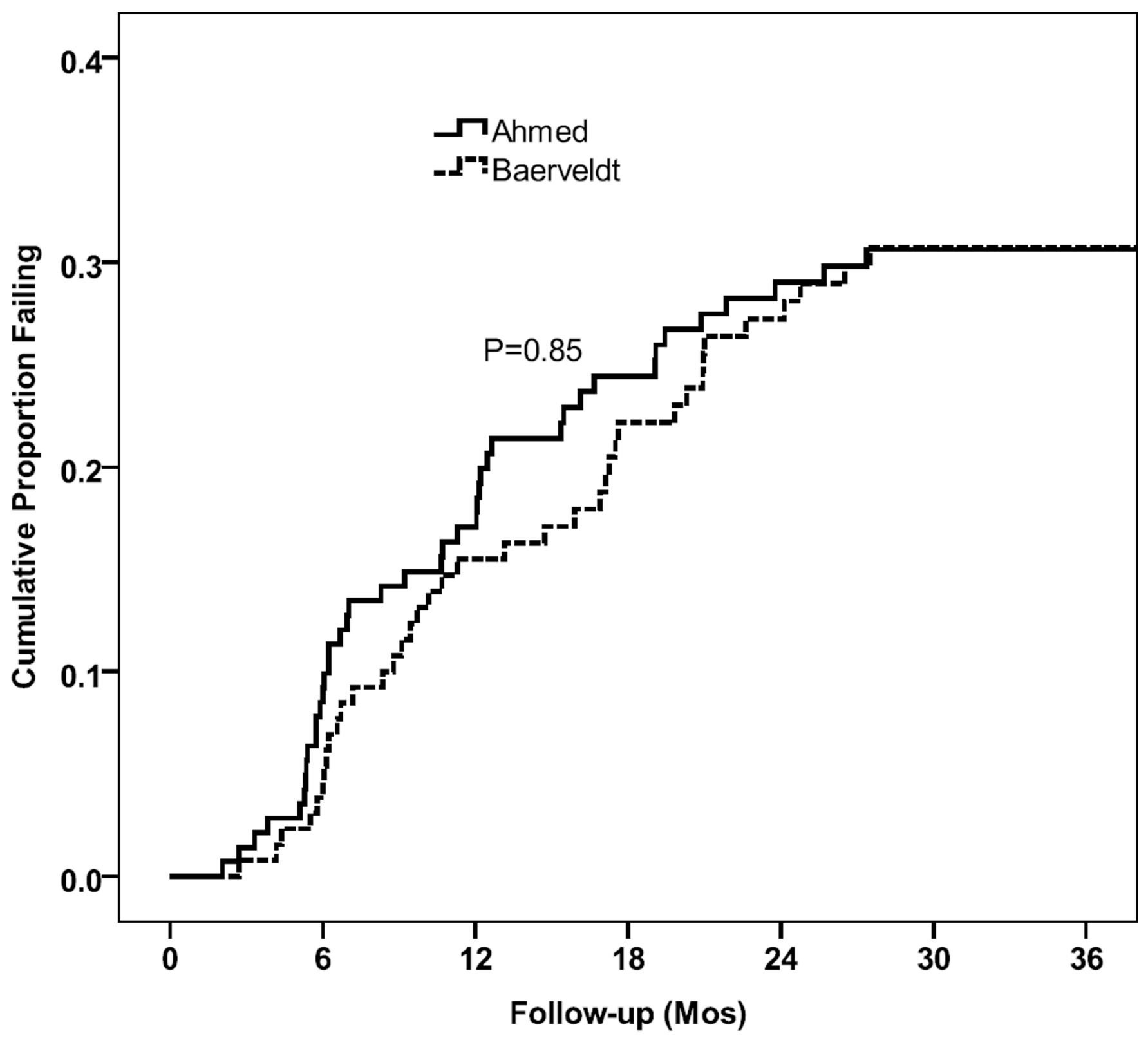

Figure 4. Kaplan-Meier cumulative surgical failure rates by randomized treatment group Kaplan-Meier survival curve of cumulative surgical failures over three years of follow-up by treatment group. 


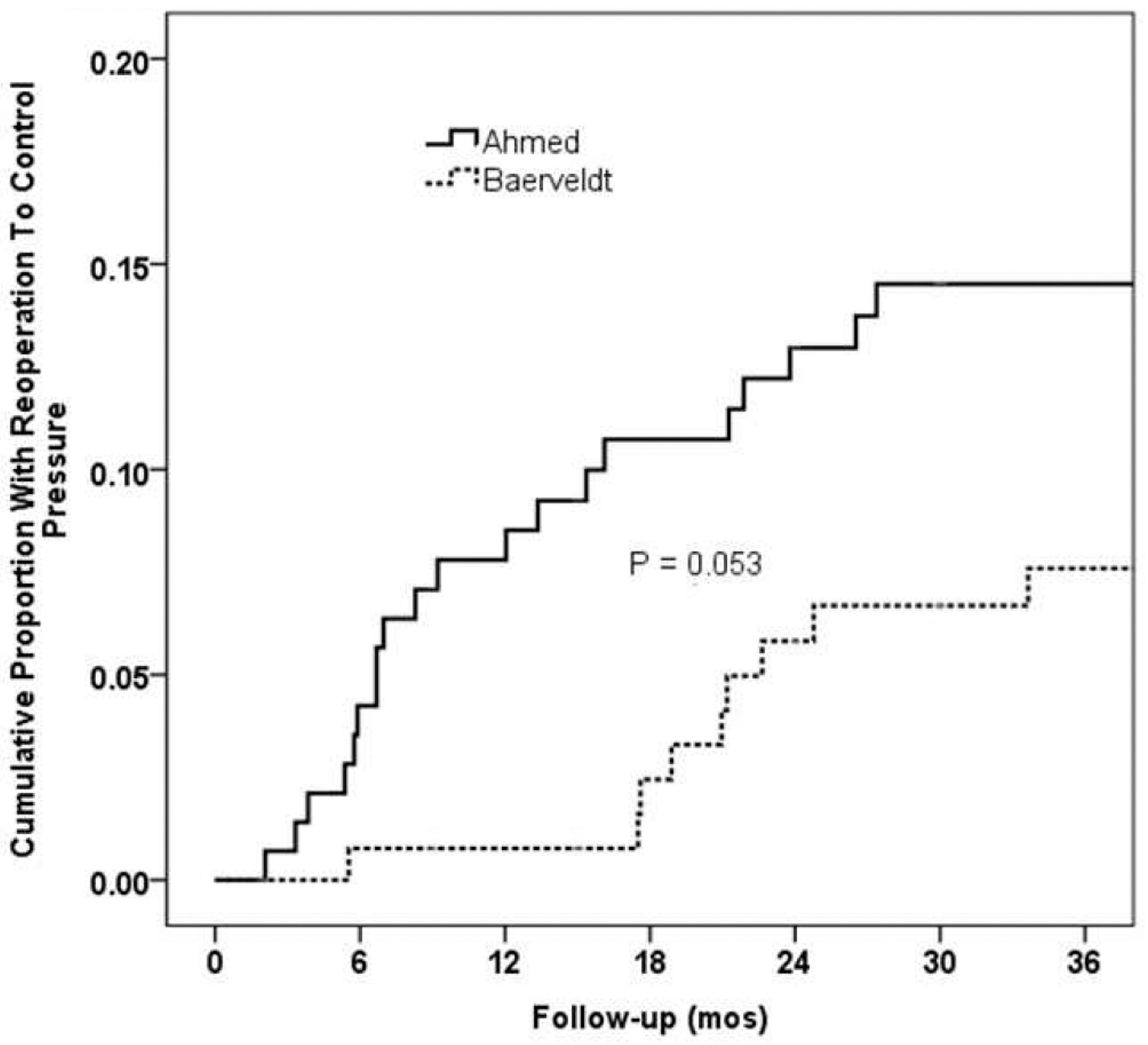

Figure 5. Kaplan-Meier cumulative reoperation rates by randomized treatment group Kaplan-Meier survival curve of cumulative reoperation rates by randomized treatment group in the first three years of follow-up. 
Table 1

Intraocular Pressure and Medical Therapy at Baseline and Follow-up in the Ahmed Baerveldt Comparison Study*

\begin{tabular}{|c|c|c|c|}
\hline & Ahmed Group & Baerveldt Group & P-value ${ }^{\dagger}$ \\
\hline \multicolumn{4}{|l|}{ Baseline } \\
\hline $\mathrm{IOP}(\mathrm{mm} \mathrm{Hg})$ & $31.2 \pm 11.2$ & $31.8 \pm 12.5$ & .71 \\
\hline Glaucoma medications & $3.4 \pm 1.1$ & $3.5 \pm 1.1$ & .34 \\
\hline $\mathrm{N}$ & 143 & 133 & \\
\hline \multicolumn{4}{|l|}{1 month } \\
\hline IOP (mm Hg) & $20.7 \pm 9.7$ & $18.0 \pm 10.0$ & 0.026 \\
\hline Glaucoma medications & $0.5 \pm 1.1$ & $1.3 \pm 1.5$ & $<0.001$ \\
\hline $\mathrm{N}$ followed (\% of baseline) & $141(99 \%)$ & $131(98 \%)$ & \\
\hline \multicolumn{4}{|l|}{3 months } \\
\hline $\mathrm{IOP}(\mathrm{mm} \mathrm{Hg})$ & $18.8 \pm 8.2$ & $16.7 \pm 8.2$ & 0.044 \\
\hline Glaucoma medications & $1.4 \pm 1.3$ & $1.2 \pm 1.3$ & 0.28 \\
\hline $\mathrm{N}$ followed (\% of baseline) & $134(94 \%)$ & $125(94 \%)$ & \\
\hline \multicolumn{4}{|l|}{6 months } \\
\hline IOP $(\mathrm{mm} \mathrm{Hg})$ & $15.7 \pm 5.3$ & $14.8 \pm 6.8$ & 0.27 \\
\hline Glaucoma medications & $1.7 \pm 1.4$ & $1.3 \pm 1.3$ & 0.010 \\
\hline $\mathrm{N}$ followed (\% of baseline) & $131(92 \%)$ & $125(94 \%)$ & \\
\hline \multicolumn{4}{|l|}{1 year } \\
\hline IOP $(\mathrm{mm} \mathrm{Hg})$ & $15.4 \pm 5.5$ & $13.4 \pm 6.9$ & 0.018 \\
\hline Glaucoma medications & $1.8 \pm 1.3$ & $1.5 \pm 1.4$ & 0.078 \\
\hline $\mathrm{N}$ followed (\% of baseline) & $133(93 \%)$ & $117(88 \%)$ & \\
\hline \multicolumn{4}{|l|}{18 months } \\
\hline $\mathrm{IOP}(\mathrm{mm} \mathrm{Hg})$ & $14.8 \pm 4.6$ & $13.3 \pm 4.6$ & 0.034 \\
\hline Glaucoma medications & $1.8 \pm 1.4$ & $1.4 \pm 1.4$ & 0.068 \\
\hline $\mathrm{N}$ followed (\% of baseline) & $121(85 \%)$ & $106(80 \%)$ & \\
\hline \multicolumn{4}{|l|}{2 years } \\
\hline $\mathrm{IOP}(\mathrm{mm} \mathrm{Hg})$ & $14.5 \pm 5.5$ & $14.2 \pm 6.0$ & 0.76 \\
\hline Glaucoma medications & $1.9 \pm 1.3$ & $1.4 \pm 1.5$ & 0.020 \\
\hline $\mathrm{N}$ followed (\% of baseline) & $122(85 \%)$ & $110(83 \%)$ & \\
\hline \multicolumn{4}{|l|}{3 years } \\
\hline $\mathrm{IOP}(\mathrm{mm} \mathrm{Hg})$ & $14.3 \pm 4.7$ & $13.1 \pm 4.5$ & 0.086 \\
\hline Glaucoma medications & $2.0 \pm 1.4$ & $1.5 \pm 1.4$ & 0.020 \\
\hline $\mathrm{N}$ followed (\% of baseline) & $106(74 \%)$ & $100(75 \%)$ & \\
\hline
\end{tabular}

Data are presented as mean \pm standard deviation $(\mathrm{SD})$.

$\mathrm{IOP}=$ intraocular pressure 
* IOP, number of medications censored after treatment failure by no light perception (NLP), reoperation for glaucoma, explantation for complication

${ }^{\dagger}$ Student t-test 
Table 2

Reasons for Treatment Failure in the Ahmed Baerveldt Comparison Study were different by treatment group

\begin{tabular}{|c|c|c|}
\hline & Ahmed Group & Baerveldt Group \\
\hline Inadequate IOP control without additional glaucoma surgery & $18(42)$ & $15(38)$ \\
\hline Reoperation to lower IOP & $16(37)$ & $7(18)$ \\
\hline Explantation for complication & $3(7)$ & $4(10)$ \\
\hline Persistent hypotony ${ }^{*}$ & $1(2)$ & $5(13)$ \\
\hline Loss of light perception & $5(12)$ & $9(23)$ \\
\hline Total & 43 & 40 \\
\hline
\end{tabular}

Data are presented as number (percentage of the total number of failures in each respective treatment allocation group). $\mathrm{P}=0.109$ (Fisher exact).

There were significantly more failures for IOP elevation and reoperation to lower IOP than other causes of failure ( $\mathrm{p}=0.034)$

$\mathrm{IOP}=$ intraocular pressure

IOP $\leq 5 \mathrm{~mm} \mathrm{Hg}$ at 2 consecutive visits after 3 months 
Table 3

Visual Acuity Results in the Ahmed Baerveldt Comparison Study

\begin{tabular}{|l|c|c|c|}
\hline & $\begin{array}{c}\text { Ahmed Group } \\
\text { N=104 }\end{array}$ & $\begin{array}{c}\text { Baerveldt Group } \\
\text { N=101 }\end{array}$ & P-value \\
\hline Snellen VA, logMAR mean \pm SD & & & \\
Baseline (n=276) & $1.07 \pm 1.01$ & $1.04 \pm 1.00$ & $.80^{\dagger}$ \\
3 years (n=205) & $1.16 \pm 1.07$ & $1.19 \pm 1.28$ & $0.83^{\dagger}$ \\
Change at 3 years (n=205) & $0.21 \pm 0.88$ & $0.26 \pm 0.74$ & $.66^{\dagger}$ \\
\hline Loss of $\geq 2$ Snellen lines at 3 years, $\mathrm{n}(\%)$ & $36(35 \%)$ & $30(30 \%)$ & $0.55^{\dagger}$ \\
Glaucoma & $14(39 \%)$ & $9(30 \%)$ & \\
Retinal disease & $8(22 \%)$ & $5(17 \%)$ & \\
Cataract & $3(8 \%)$ & $4(13 \%)$ & \\
Other & $8(22 \%)$ & $11(37 \%)$ & \\
Unknown & $4(11 \%)$ & $1(3 \%)$ & \\
\hline
\end{tabular}

* Patients may have more than one reason for decreased vision. In the one year manuscript, a change in acuity from counting fingers (CF) to hand motions (HM) and a change from HM to light perception (LP) was considered a two Snellen line loss. In the current manuscript these are considered a one Snellen line loss.

${ }^{\dagger}$ Two sided Student t-test

${ }^{\ddagger}$ Fisher exact test

VA = Visual Acuity, Logmar $=$ Logarithm of the Minium Angle of Resolution visual acuity, SD $=$ Standard Deviation 


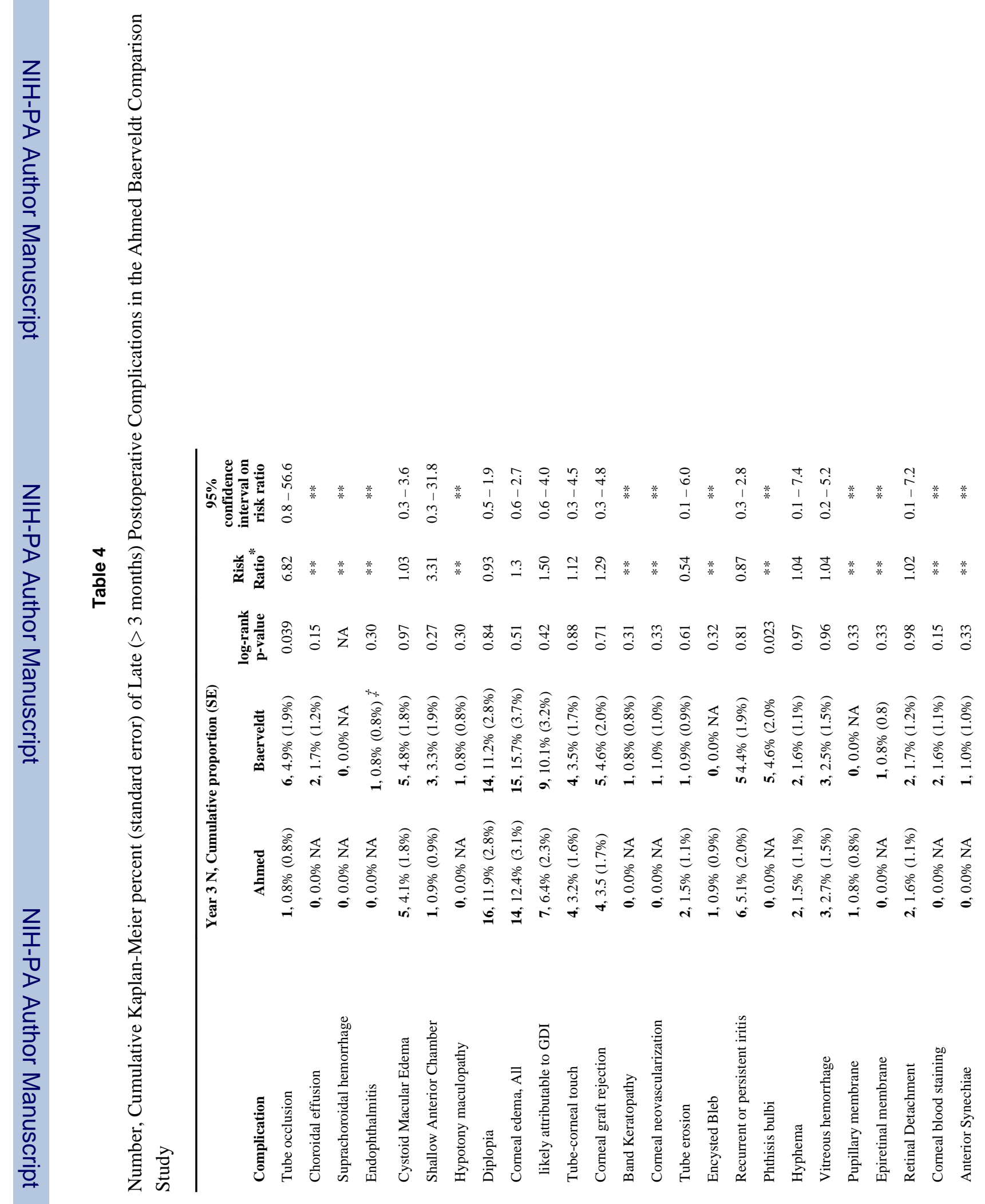




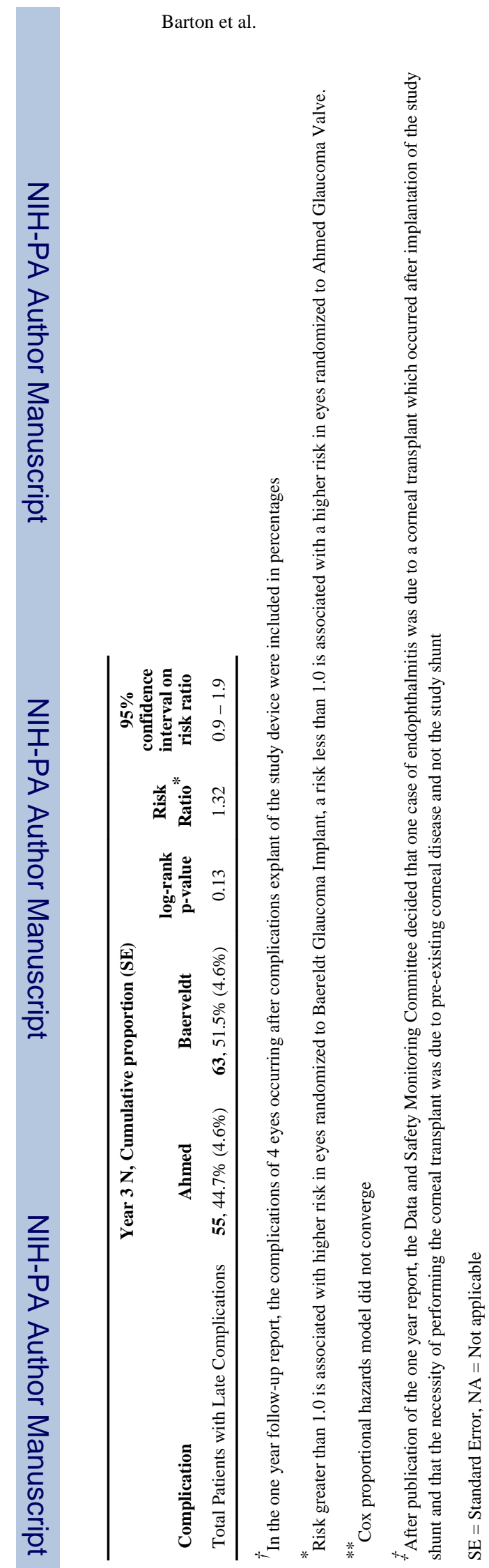

Ophthalmology. Author manuscript; available in PMC 2015 August 01. 


\section{Table 5}

Complications by Neovascular Glaucoma (NVG) versus other strata $(1,2,4)$.

\begin{tabular}{|c|c|c|c|}
\hline \multirow[b]{2}{*}{ Complication } & \multicolumn{2}{|c|}{$\begin{array}{l}\text { Year } 3 \text { N, Cumulative proportion } \\
\text { (Standard Error)(SE) }\end{array}$} & \multirow{2}{*}{$\begin{array}{c}\text { log-rank } \\
\text { p-value }\end{array}$} \\
\hline & NVG & Other Diagnosis & \\
\hline Tube occlusion & $35.5 \%(3.2 \%)$ & $4,2.3 \%(1.1 \%)$ & 0.31 \\
\hline Choroidal effusion & $11.8 \%(1.7 \%)$ & $\mathbf{1}, 0.6 \%(0.6 \%)$ & 0.42 \\
\hline Suprachoroidal hemorrhage & 0 $0.0 \%$ NA & $00.0 \%$ NA & NA \\
\hline Endophthalmitis & $\mathbf{0} 0.0 \% \mathrm{NA}$ & $10.5 \%(0.5 \%)$ & 0.54 \\
\hline Cystoid Macular Edema & $11.9 \%(1.9 \%)$ & $95.2 \%(1.7 \%)$ & 0.29 \\
\hline Shallow Anterior Chamber & $26.1 \%(4.2 \%)$ & $21.5 \%(1.0 \%)$ & 0.13 \\
\hline Hypotony maculopathy & $10.5 \%(0.5 \%)$ & 0 $0.0 \%$ NA & 0.54 \\
\hline Diplopia & $46.1 \%(3.0 \%)$ & $2614.4 \%(2.6 \%)$ & 0.085 \\
\hline Corneal edema, All & $25.1 \%(3.6 \%)$ & $2717.8 \%(3.1 \%)$ & 0.039 \\
\hline Tube-corneal touch & $35.4 \%(3.0 \%)$ & $53.0 \%(1.3 \%)$ & 0.42 \\
\hline Corneal graft rejection & $\mathbf{0} 0.0 \% \mathrm{NA}$ & $95.4 \%(1.8 \%)$ & 0.079 \\
\hline Band Keratopathy & $11.4 \%(1.4 \%)$ & $\mathbf{0} 0.0 \%$ NA & 0.10 \\
\hline Corneal neovascularization & 0 $0.0 \%$ NA & $10.7 \%(0.7 \%)$ & 0.59 \\
\hline Anterior Synechiae & 0 $0.0 \%$ NA & $10.7 \%(0.7 \%)$ & 0.59 \\
\hline Tube erosion & $\mathbf{1} 2.0 \%(1.9 \%)$ & $21.2 \%(0.8 \%)$ & 0.74 \\
\hline Encysted Bleb & 0 $0.0 \%$ NA & $10.6 \%(0.6 \%)$ & 0.56 \\
\hline Recurrent or persistent iritis & $23.5 \%(2.4 \%)$ & $95.2 \%(1.7 \%)$ & 0.55 \\
\hline Phthisis bulbi & $47.8 \%(3.8 \%)$ & $10.5 \%(0.5 \%)$ & 0.004 \\
\hline Hyphema & $45.9 \%(2.9 \%)$ & $\mathbf{0} 0.0 \% \mathrm{NA}$ & 0.001 \\
\hline Vitreous hemorrhage & $610.2 \%(4.0 \%)$ & 0 $0.0 \%$ NA & $<0.001$ \\
\hline Pupillary membrane & $11.6 \%(1.6 \%)$ & 0 $0.0 \%$ NA & 0.089 \\
\hline Epiretinal membrane & $11.4 \%(1.4 \%)$ & $\mathbf{0} 0.0 \% \mathrm{NA}$ & 0.10 \\
\hline Retinal Detachment & $46.4 \%(3.1 \%)$ & $00.0 \% \mathrm{NA}$ & 0.001 \\
\hline Corneal blood staining & $22.8 \%(2.0 \%)$ & $\mathbf{0} 0.0 \% \mathrm{NA}$ & 0.020 \\
\hline Total Patients with Late Complications & $3453.0 \%(6.5 \%)$ & $\mathbf{8 4} 46.4 \%(3.8 \%)$ & 0.57 \\
\hline \multicolumn{4}{|c|}{$\begin{array}{l}+ \text { In the one year follow-up report, the complications of } 4 \text { eyes occurring after complications explant of the study device were included in } \\
\text { percentages }\end{array}$} \\
\hline
\end{tabular}

Ophthalmology. Author manuscript; available in PMC 2015 August 01. 
Table 6

Complications Associated with Reoperation or Vision Loss

\begin{tabular}{|c|c|c|}
\hline & $\begin{array}{l}\text { Ahmed Group } \\
\quad(\mathbf{n}=\mathbf{1 0 9})\end{array}$ & $\begin{array}{l}\text { Baerveldt Group } \\
\quad(\mathbf{n}=107)\end{array}$ \\
\hline Reoperation for complications & $12(11 \%)$ & $21(20 \%)$ \\
\hline Vision loss of $\geq 2$ Snellen lines ${ }^{\dagger}$ & $12(11 \%)$ & $17(16 \%)$ \\
\hline Total Patients with Serious Complications & $24(22 \%)$ & $38(36 \%)$ \\
\hline
\end{tabular}

Data are presented as number (percentage).

* Total Numbers in this table are based on the number of participants who had a 36 month vision measured and/or had a previous complications reoperation.

${ }^{\dagger}$ Some patients did not have Snellen Visual Acuity at 1 year because they missed the 1 year visit. 